\title{
Risk factors associated with provoked pulmonary embolism
}

\author{
Endri Gjonbrataj, ${ }^{1,}$, Ji Na Kim, ${ }^{2,}$, Juarda Gjonbrataj $^{1,3}$, Hye In Jung $^{1}$, Hyun Jung Kim ${ }^{1}$, and Won-Il Choi ${ }^{1}$
}

${ }^{1}$ Department of Internal Medicine, Keimyung University School of Medicine, Daegu; ${ }^{2}$ Department of Internal Medicine, Daegu Fatima Hospital, Daegu, Korea; ${ }^{3}$ Department of Internal Medicine, Mother Theresa University Hospital Centre, Tirana, Albania

\section{Received: April 26, 2015 \\ Revised : July 17, 2015 \\ Accepted: August 13, 2015}

\section{Correspondence to}

Won-Il Choi, M.D.

Department of Internal Medicine, Keimyung University School of Medicine, 56 Dalseong-ro, Junggu, Daegu 41931, Korea

Tel: +82-53-250-7572

Fax: +82-53-250-8379

E-mail: wichoi@dsmc.or.kr

*These authors contributed equally to this work.
Background/Aims: This study aimed to investigate the risk factors associated with provoked pulmonary embolism (PE).

Methods: This retrospective cohort study included 237 patients with PE. Patients that had transient risk factors at diagnosis were classified as having provoked PE, with the remaining patients being classified as having unprovoked PE. The baseline clinical characteristics and factors associated with coagulation were compared. We evaluated the risk factors associated with provoked PE.

Results: Of the 237 PE patients, 73 (30.8\%) had provoked PE. The rate of respiratory failure and infection, as well as the disseminated intravascular coagulation score and ratio of right ventricular diameter to left ventricular diameter were significantly higher in patients with provoked PE than in those with unprovoked $\mathrm{PE}$. The protein and activity levels associated with coagulation, including protein $\mathrm{C}$ antigen, protein $\mathrm{S}$ antigen, protein $\mathrm{S}$ activity, anti-thrombin III antigen, and factor VIII, were significantly lower in patients with provoked PE than in those with unprovoked PE. Multivariate analysis showed that infection (odds ratio [OR], 3.2; $95 \%$ confidence interval [CI], 1.4 to 7.4 ) and protein S activity (OR, 0.97; 95\% CI, 0.95 to 0.99 ) were significantly associated with provoked PE.

Conclusions: Protein S activity and presence of infection were important factors associated with provoked PE. We should pay attention to the presence of infection in patients with provoked PE.

Keywords: Coagulation; Infection; Protein S; Provoked; Pulmonary embolism

\section{INTRODUCTION}

Pulmonary embolism (PE) - as a subset of venous thromboembolism (VTE)—is a common, potentially lethal disorder that affects hospitalized and non-hospitalized patients. It recurs frequently and is often overlooked, resulting in long-term complications. $\mathrm{PE}$ is the third most common cause of hospital-related death and the most common preventable cause of hospital-related death $[1,2]$.

Although the pathophysiology of PE is not well understood, the predisposing factors broadly fit Virchow's triad of blood stasis, endothelial injury, and enhanced blood coagulability [3]. Pulmonary emboli usually arise from the thrombi that originated in the deep venous system of the lower extremities. PE occurs in approximately $15 \%$ to $32 \%$ of cases following deep vein thrombosis (DVT) in the lower extremities [4].

A provoked PE is associated with acquired risk factors, either transient or persistent, whereas an unprovoked or idiopathic PE is associated with no apparent clinical risk factors [5]. Death, recurrence, and long-term mortality can often be avoided by identifying and treating the risk factors. The risk factors for provoked PE include 
age, personal history of VTE, active malignancy, or other disabling conditions such as heart or respiratory failure, coagulation disorders, hormone replacement therapy, oral contraception, immobilization, and surgery or trauma within the last 3 months [6]. However cancer associated VTE can be classified separated from provoked VTE [7]. Patients with unprovoked PE-when compared with their provoked counterparts-are at higher risk for recurrent PE [8,9], cardiovascular events [10], cancer [11], and chronic thromboembolic pulmonary hypertension [8]. The risk of recurrence is low if the VTE is provoked by surgery, intermediate if provoked by a nonsurgical risk factor, and high if unprovoked [12-16].

In a population-based prospective cohort study with 21,680 participants from six communities in the USA, there were 366 validated thromboses during a 10-year follow-up period. Among the 366 patients with thrombosis, 99 were diagnosed as having PE. Fifty patients had idiopathic $\mathrm{PE}$, and 49 patients had a secondary (provoked) PE [17]. Although several studies have evaluated the factors that influence the development and recurrence of unprovoked $\mathrm{PE}$, the information on the risk factors associated with provoked PE is limited. Therefore, we aimed to investigate the risk factors associated with provoked PE, which may result in earlier evaluation of the patients at high risk for PE, and earlier decisions about prophylactic measures.

\section{METHODS}

\section{Study design}

This retrospective cohort study was conducted between January 2009 and December 2012. This study was approved by the institutional review board at Keimyung University Dongsan Medical Center with waived informed consent.

\section{Study subjects}

During the study period, 583 new adult cases aged $\geq 20$ years were diagnosed as acute PE in our hospital. We excluded patients who had active cancer before diagnosis of PE [7]. We selected cases whose coagulation factors and profiles were measured at the time of $\mathrm{PE}$ diagnosis before starting warfarin treatment. A total of $237 \mathrm{PE}$ patients were enrolled (Fig. 1).

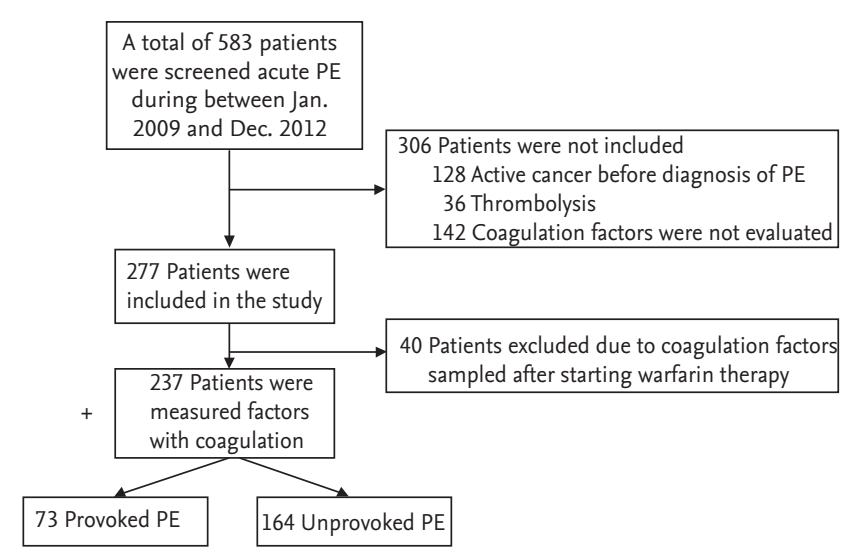

Figure 1. Flow-chart of the study. PE, pulmonary embolism.

\section{Imaging studies}

$\mathrm{PE}$ was diagnosed based on the presence of intraluminal filling defects in the pulmonary arteries on chest computed tomography (CT) or CT pulmonary angiography, or the findings of a ventilation perfusion scan [18]. DVT diagnosis was confirmed via ultrasound examination or CT venogram of the lower extremities in patients with clinically suspected PE.

\section{Study methods}

We reviewed the electronic medical records of all PE patients. We defined provoked PE as patient has trane sient (within 3 months) risk factors such as surgery, trauma, immobility (bedbound), pregnancy or puerperium, or history of hormonal therapy (oral contraceptive or hormone replacement therapy) [19]. Patients who do not have transient risk factors, we regarded them as an unprovoked PE. The risk factors for PE were as follows: renal dysfunction, defined as serum creatinine level > $1.3 \mathrm{mg} / \mathrm{dL}$; active cancer, defined as treatment with an anti-cancer agent within 3 months of PE diagnosis; and shock, defined as a systolic blood pressure of $<90$ mmHg. CT was performed using a 16- or 128-slice detector. The reconstruction interval of the scan was $3 \mathrm{~mm}$. The right ventricular to left ventricular diameter (RV/ LV) ratio was calculated using CT images showing the interventricular septum and myocardium from the longitudinal axis of the heart $[20,21]$. We retrospectively cola lected the clinical characteristics and laboratory data on factors such as co-morbidity, symptoms, chest CT findings, vital signs, RV/LV ratio, N-terminal prohormone of brain natriuretic peptide, and complete blood count 
at the time of PE diagnosis. Coagulation profiles were measured before starting warfarin therapy. The dissemb inated intravascular coagulation (DIC) score was calcue lated based on the International Society on Thrombosis and Haemostasis scoring system [22].

Protein $\mathrm{C}$ and protein $\mathrm{S}$ activities were measured using factor V and VII as substrates (Diagnostica Stago, Asnieres, France). Total protein C, total protein S, and free protein $\mathrm{S}$ were measured by radial immunodiffusion. Antithrombin III (AT-III), factor VIII, and factor IX were automatically measured (ACL Top 500, Instrumentation Laboratory, Bedford, MA, USA).

\section{Statistical analysis}

We performed a univariate analysis using logistic regression to determine the variables that were significantly associated with provoked PE. We included in the multivariate analysis all the variables with a $p<0.2$ on univariate analysis. Multivariate logistic regression analysis identified the independent variables associated with provoked PE. All tests of significance were twotailed, and a $p$ value of 0.05 was considered significant. Results were analysed with SPSS version 20.0 (IBM Co., Armonk, NY, USA). Values are expressed as mean \pm standard deviation.

\section{RESULTS}

Risk factors for provoked PE were present in 31\% of cases. The majority of patients with provoked PE were females with a mean age of 64.8 years. Among 73 provoked $\mathrm{PE}, 33$ patients were related with surgery and 40 patients were related with immobilization. The clinical characteristics between patients with provoked and unprovoked PE were not significantly different. However, the rate of respiratory failure and infection, as well as the DIC score and RV/LV ratio were higher in patients with provoked PE than in those with unprovoked PE (1.3-, 2-, 1.3-, and 1.25-fold higher, respectively). Although not statistically significant, the 30-day mortality was 2-fold higher in patients with provoked PE than in those with unprovoked PE. Meanwhile, the recurrence rate in patients with provoked $\mathrm{PE}$ was half of that in patients with unprovoked PE. All demographic, clinical, and laboratory data are summarised in Table 1.
Protein and activity levels associated with coagulation were lower in patients with provoked PE than in those with unprovoked PE; the difference was statistically significant for protein $\mathrm{C}$ antigen, protein $\mathrm{S}$ antigen, protein S activity, and AT-III antigen (Table 2).

As shown in Table 3, the multivariate analysis revealed a significant association between provoked PE, infection, and protein $\mathrm{S}$ activity. Infection and protein S activity were the only independent factors associated with provoked PE. The rate of infection was 2-fold higher in patients with provoked PE than in those with unprovoked PE. The most frequent infection associated with $\mathrm{PE}$ was pneumonia, with its frequency being 2-fold higher in patients with unprovoked PE than in those with provoked PE (Table 3).

\section{DISCUSSION}

We aimed to investigate the risk factors associated with provoked PE, including the alteration of the factors associated with coagulation. We found infection and protein $\mathrm{S}$ activity as independent variables associated with provoked PE.

The infection rate was 2-fold higher in patients with provoked PE than in those with unprovoked PE. The most frequent infection associated with $\mathrm{PE}$ was pneumonia. However, frequency of pneumonia was 2-fold higher in patients with unprovoked PE than in those with provoked PE. The association between PE and infection is supported by several studies [23-26]. The odds ratio ranged from 1.7 to 5.0 in other studies $[24,25,27,28]$. In our study, the odd ratio of infection related to provoked PE was 3.2 (95\% confidence interval, 1.4 to 7.4).

Meanwhile, sepsis is reported to be associated with haemostatic abnormalities ranging from localized VTE to acute DIC [29]. In sepsis-induced DIC, the activation of the extrinsic coagulation pathway via tissue factor appears to be the primary event [23]. The initial hypercoagulation is followed by the depletion of clotting factors and organ damage, followed by haemorrhage due to consumption coagulopathy [23]. Early DIC is characterized by thrombosis and decreased protein $\mathrm{S}$ activity as well as unaltered level of protein S antigen [24]. In our study, protein $\mathrm{S}$ activity was lower in patients with provoked PE (56.3\%) than in those with unprovoked PE 
Table 1. Baseline characteristics for the 237 patients with pulmonary embolism

\begin{tabular}{|c|c|c|c|c|}
\hline Variable & $\begin{array}{l}\text { Overall } \\
(\mathrm{n}=237)\end{array}$ & $\begin{array}{l}\text { Unprovoked PE } \\
\qquad(\mathrm{n}=164)\end{array}$ & $\begin{array}{l}\text { Provoked PE } \\
\quad(\mathrm{n}=73)\end{array}$ & $p$ value \\
\hline Age, yr & $66.2 \pm 13.9$ & $66.8 \pm 13.5$ & $64.8 \pm 14.9$ & 0.31 \\
\hline Male sex & $84(35 \cdot 4)$ & $61(37.2)$ & $23(31.5)$ & 0.40 \\
\hline Body mass index & $24.1 \pm 4$ & $23.9 \pm 4.2$ & $24.6 \pm 3 \cdot 3$ & 0.27 \\
\hline \multicolumn{5}{|l|}{ Comorbidity } \\
\hline Heart failure & $33(14)$ & $20(12.2)$ & $13(17.8)$ & 0.25 \\
\hline Respiratory failure & $150(63 \cdot 3)$ & $96(58.5)$ & $54(74)$ & 0.02 \\
\hline Renal dysfunction & $31(13.1)$ & $19(11.6)$ & $12(16.4)$ & 0.31 \\
\hline Previous DVT or PE & $13(5 \cdot 5)$ & $11(6.7)$ & $2(2.7)$ & 0.22 \\
\hline DIC score ${ }^{a}$ & $2.1 \pm 1.4$ & $1.9 \pm 1.4$ & $2.4 \pm 1.5$ & 0.04 \\
\hline Infection & $86(36.3)$ & $45(27 \cdot 4)$ & $41(56.2)$ & $<0.01$ \\
\hline Respiratory tract infection & $42(48.8)$ & $27(60)$ & $15(36.6)$ & \\
\hline Urinary tract infection & $6(7)$ & $5(11.1)$ & $1(2.4)$ & \\
\hline Wound infection & $6(7)$ & $1(2.2)$ & $5(12.2)$ & \\
\hline Intra-abdominal infection & $5(5.8)$ & $4(8.9)$ & $1(2.4)$ & \\
\hline Other site infection & $23(26.7)$ & $7(15 \cdot 5)$ & $16(39)$ & \\
\hline Unknown infection & $4(4 \cdot 6)$ & $1(2.2)$ & $3(7 \cdot 3)$ & \\
\hline \multicolumn{5}{|l|}{ Clinical findings } \\
\hline Haemoptysis & $16(6.7)$ & $9(5 \cdot 5)$ & $7(9.6)$ & 0.25 \\
\hline Chest pain & $37(15 \cdot 6)$ & $27(16.5)$ & $10(13.7)$ & 0.59 \\
\hline Altered mental state ${ }^{b}$ & $18(7 \cdot 6)$ & $11(6.7)$ & $7(9.6)$ & 0.41 \\
\hline Systolic blood pressure, $\mathrm{mmHg}^{\mathrm{c}}$ & $122.6 \pm 21.5$ & $123 \pm 20.4$ & $121.7 \pm 23.9$ & 0.66 \\
\hline Shock & $14(5 \cdot 9)$ & $7(4.27)$ & $7(9.56)$ & 0.11 \\
\hline \multicolumn{5}{|l|}{$\begin{array}{l}\text { Cardiac chamber ratio and cardiac } \\
\text { biomarker }\end{array}$} \\
\hline RV/LV ratio & $1.1 \pm 0.5$ & $1.0 \pm 0.4$ & $1.3 \pm 0.6$ & $<0.01$ \\
\hline NT pro-BNP, ng/L & $3,005.6 \pm 4,669.7$ & $2,617 \cdot 5 \pm 4,001$ & $3,905 \cdot 5 \pm 5,895$ & 0.13 \\
\hline WBC, cells $/ \mu \mathrm{L}$ & $9,436 \pm 4,239$ & $9,180 \pm 4,135$ & $10,011 \pm 4,439$ & 0.16 \\
\hline D-dimer, $\mu \mathrm{g} / \mathrm{mL}$ & $6 \pm 7 \cdot 3$ & $5.6 \pm 7.8$ & $6.9 \pm 5.9$ & 0.33 \\
\hline BUN, mg/dL & $19.9 \pm 11.7$ & $20 \pm 11.6$ & $19.6 \pm 11.9$ & 0.83 \\
\hline P'T, sec & $11.6 \pm 3.6$ & $11.4 \pm 3.4$ & $12.1 \pm 4.2$ & 0.19 \\
\hline Platelets, cells $/ \mu \mathrm{L}$ & $251,729 \pm 112,231$ & $249,377 \pm 116,297$ & $257,014 \pm 103,082$ & 0.63 \\
\hline SIRS total score & $38(16)$ & $23(14)$ & $15(20.5)$ & 0.27 \\
\hline \multicolumn{5}{|l|}{ Outcome } \\
\hline 30-Day mortality & $10(4.22)$ & $5(3.05)$ & $5(6.85)$ & 0.18 \\
\hline PESI & $85.9 \pm 28.8$ & $85.8 \pm 27.6$ & $86.1 \pm 31.6$ & 0.96 \\
\hline Lower extremity DVT & $77(32.5)$ & $56(34)$ & $21(28.7)$ & 0.42 \\
\hline
\end{tabular}

Values are presented as mean $\pm \mathrm{SD}$ or number $(\%)$.

$\mathrm{PE}$, pulmonary embolism; DVT, deep vein thrombosis; DIC, disseminated intravascular coagulation; RV, right ventricle; LV, left ventricle; NT pro-BNP, N-terminal prohormone of brain natriuretic peptide; WBC, white blood cells; BUN, blood urea nitrogen; PT, prothrombin time; SIRS, systemic inflammatory response syndrome; PESI, pulmonary embolism severity index. ${ }^{a}$ DIC score was based on the International Society on Thrombosis and Haemostasis scoring system.

${ }^{\mathrm{b}}$ Altered mental status was defined as disorientation, stupor, or coma.

${ }^{\mathrm{C}}$ Shock was defined as systolic blood pressure $<90 \mathrm{mmHg}$. 
Table 2. Factors associated with coagulation between patients with unprovoked and provoked pulmonary embolism

\begin{tabular}{lcccc}
\hline Coagulation profile & $\begin{array}{c}\text { Overall } \\
(\mathrm{n}=237)\end{array}$ & $\begin{array}{c}\text { Unprovoked PE } \\
(\mathrm{n}=164)\end{array}$ & $\begin{array}{c}\text { Provoked PE } \\
(\mathrm{n}=73)\end{array}$ & $p$ value \\
\hline Protein C Ag, \% & $50.7 \pm 48.7$ & $58 \pm 48.9$ & $36.5 \pm 45.6$ & $<0.01$ \\
Protein C activity, \% & $82.6 \pm 33.6$ & $84 \pm 34.2$ & $79.4 \pm 32.4$ & 0.34 \\
Protein S Ag, \% & $50.1 \pm 42$ & $57.2 \pm 41.3$ & $35.7 \pm 40.1$ & $<0.01$ \\
Protein S Ag, free form, \% & $56.2 \pm 30.5$ & $57.6 \pm 29.5$ & $53.7 \pm 32.5$ & 0.59 \\
Protein S activity, \% & $66.5 \pm 25$ & $71 \pm 24.5$ & $56.3 \pm 23.2$ & $<0.01$ \\
Antithrombin III Ag, \% & $74.7 \pm 30.9$ & $80 \pm 28.1$ & $64.3 \pm 33.7$ & $<0.01$ \\
Factor VII, \% & $69.7 \pm 41.2$ & $68.1 \pm 38$ & $73.3 \pm 47.4$ & $163 \pm 40.3$ \\
Factor VIII, \% & $175.7 \pm 56.5$ & $181.7 \pm 62$ & 9.49 & 0.03 \\
Factor IX, \% & $90 \pm 44$ & $89.9 \pm 45.8$ & $90.2 \pm 40$ & 0.96 \\
\hline
\end{tabular}

Values are presented as mean $\pm \mathrm{SD}$.

$\mathrm{PE}$, pulmonary embolism; Ag, antigen.

Table 3. Multivariate analysis with the provoked pulmonary embolism group as the dependent variable

\begin{tabular}{lccccc}
\hline Variable & Coefficient & SE & $p$ value & OR & $95 \%$ CI \\
\hline Respiratory failure & 0.51 & 0.46 & 0.27 & 1.66 & 3.25 \\
Infection & 1.18 & 0.42 & $<0.01$ & $0.67-4.10$ & $1.42-7.42$ \\
Protein C Ag & 1.18 & 0.01 & 0.89 & 0.99 & $0.98-1.02$ \\
Protein S Ag & -0.003 & 0.01 & 0.81 & 0.99 & $0.97-1.02$ \\
Protein S activity & -0.026 & 0.01 & 0.02 & 0.97 & $0.95-0.99$ \\
Antithrombin III Ag & -0.005 & 0.01 & 0.56 & 0.99 & $0.98-1.01$ \\
Factor VIII & -0.007 & 0.005 & 0.15 & 0.99 & $0.98-1.00$ \\
DIC score & 0.038 & 0.14 & 0.78 & 1.04 & $0.79-1.36$ \\
\hline
\end{tabular}

SE, standard error; OR, odds ratio; CI, confidence interval; Ag, antigen; DIC, disseminated intravascular coagulation.

(71\%), whereas the DIC score was higher in patients with provoked PE (2.4) than in those with unprovoked PE (1.9). The presence of infection and low protein S activity in patients with provoked PE support our idea that provoked PE is an earlier form of DIC.

Other coagulation factors such as protein $\mathrm{C}$ antigen, protein S antigen, AT-III, factor VIII, and factor IX were not associated with provoked PE. In the present study, the AT-III level was lower in patients with provoked PE. The risk of VTE in patients with AT-III deficiency is higher than in those with other coagulation abnormalities [25]. However, the multivariate analysis showed that the AT-III level is not related with provoked PE. Moreover, we did not find any significant difference between factor IX levels in patients with provoked and unprovoked PE.
In our study, patients with unprovoked PE had higher factor VIII levels than those with provoked PE (181.7\% vs. $163 \%, p=0.03)$. Our findings are in agreement with the well-known association between idiopathic DVT and increased factor VIII levels [26,27].

Although we did not study the genetic abnormalities in patients with protein $\mathrm{S}$ deficiency, it is suggested that protein $\mathrm{S}$ deficiency might be an acquired form. There was no family history or recurrent thrombosis history in patients with protein $\mathrm{S}$ deficiency. Furthermore the mean age of thrombosis patients was 66.2 years in our study, suggesting that protein S deficiency might be acquired; on the other hand, its hereditary form presents at an earlier age-in the third decade of life-with thrombosis $[28,30]$.

In our study, a similar number of patients with pro- 
voked and unprovoked PE developed shock during their clinical course. There was no significant statistical difference in the 30-day mortality between the two groups. The 30-day mortality was 3.05\% and $6.85 \%$ in patients with unprovoked and provoked $\mathrm{PE}$, respectively. The underlying conditions and comorbidities such as higher frequency of respiratory failure and higher DIC score and higher rate of infection in patients with provoked PE may increase mortality compared with unprovoked PE. One of the factors that may contribute to the higher mortality observed in patients with provoked PE is the higher RV/LV ratio compared to patients with unprovoked PE.

Our study has several limitations. This study was limited by the relative small sample size based on single center and the retrospective data collection. Cases were selected based on measuring coagulation factors, which resulted in more than half of the PE patients were not included during study period. However, this study may provide new insights into of potential triggering factors for provoked PE.

A provoked PE is associated with acquired risk factors, either transient or persistent. The risk factors for provoked PE considered as surgery or trauma, immobilization, hormone replacement therapy, or oral contraception. However infection or transient coagulation abnormalities were not included in transient risk factors for provoked PE. In the present study demonstrated that the presence of infection and reduced protein $\mathrm{S}$ activity were found to be important factors associated with provoked PE. PE develops after surgery, trauma, or immobilization; we should carefully investigate the presence of infection.

\section{KEY MESSAGE}

1. Reduced protein S activity and the presence of infection were associated with provoked pulmonary embolism (PE).

2. This findings support that acquired form of proteins $\mathrm{S}$ deficiency in the presence of infection may responsible for developing provoked PE.

3. We should pay attention to the presence of infection in patients with provoked PE.

\section{Conflict of interest}

No potential conflict of interest relevant to this article was reported.

\section{Acknowledgments}

The biospecimens for this study were provided by the Keimyung Human Bio-Resource Bank (KHBB), a member of the National Biobank of Korea, which is supported by the Ministry of Health and Welfare. All samples derived from the National Biobank of Korea were obtained with informed consent under Institutional Review Board-approved protocols. We thank Ms. Jin Hee Jeon who did data collection.

\section{REFERENCES}

1. Lindblad B, Eriksson A, Bergqvist D. Autopsy-verified pulmonary embolism in a surgical department: analysis of the period from 1951 to 1988. Br J Surg 1991;78:849-852.

2. Sandler DA, Martin JF. Autopsy proven pulmonary embolism in hospital patients: are we detecting enough deep vein thrombosis? J R Soc Med 1989;82:203-205.

3. Bagot CN, Arya R. Virchow and his triad: a question of attribution. Br J Haematol 2008;143:180-190.

4. Kucher N. Clinical practice: deep-vein thrombosis of the upper extremities. N Engl J Med 2011;364:861-869.

5. Lapner ST, Kearon C. Diagnosis and management of pulmonary embolism. BMJ 2013;346:f757.

6. British Thoracic Society Standards of Care Committee Pulmonary Embolism Guideline Development Group. British Thoracic Society guidelines for the management of suspected acute pulmonary embolism. Thorax 2003;58:470-483.

7. Howard LS, Hughes RJ. NICE guideline: management of venous thromboembolic diseases and role of thrombophilia testing. Thorax 2013;68:391-393.

8. Carson JL, Kelley MA, Duff A, et al. The clinical course of pulmonary embolism. N Engl J Med 1992;326:1240-1245.

9. Christiansen SC, Cannegieter SC, Koster T, Vandenbroucke JP, Rosendaal FR. Thrombophilia, clinical factors, and recurrent venous thrombotic events. JAMA 2005;293:2352-2361.

10. Klok FA, Mos IC, Broek L, et al. Risk of arterial cardiovascular events in patients after pulmonary embolism. Blood 2009;114:1484-1488. 
11. Sorensen HT, Mellemkjaer L, Steffensen FH, Olsen JH, Nielsen GL. The risk of a diagnosis of cancer after primary deep venous thrombosis or pulmonary embolism. N Engl J Med 1998;338:1169-1173.

12. Kearon C, Ginsberg JS, Anderson DR, et al. Comparison of 1 month with 3 months of anticoagulation for a first episode of venous thromboembolism associated with a transient risk factor. J Thromb Haemost 2004;2:743-749.

13. Levine MN, Hirsh J, Gent M, et al. Optimal duration of oral anticoagulant therapy: a randomized trial comparing four weeks with three months of warfarin in patients with proximal deep vein thrombosis. Thromb Haemost 1995;74:606-611.

14. Schulman S, Rhedin AS, Lindmarker P, et al. A comparison of six weeks with six months of oral anticoagulant therapy after a first episode of venous thromboembolism: duration of Anticoagulation Trial Study Group. N Engl J Med 1995;332:1661-1665.

15. Prandoni P, Lensing AW, Buller HR, et al. Deep-vein thrombosis and the incidence of subsequent symptomatic cancer. N Engl J Med 1992;327:1128-1133.

16. Pinede L, Ninet J, Duhaut $P$, et al. Comparison of 3 and 6 months of oral anticoagulant therapy after a first episode of proximal deep vein thrombosis or pulmonary embolism and comparison of 6 and 12 weeks of therapy after isolated calf deep vein thrombosis. Circulation 2001;103:2453-2460.

17. Cushman M, Tsai AW, White RH, et al. Deep vein thrombosis and pulmonary embolism in two cohorts: the longitudinal investigation of thromboembolism etiology. Am J Med 2004;117:19-25.

18. Huisman MV, Klok FA. Diagnostic management of acute deep vein thrombosis and pulmonary embolism. J Thromb Haemost 2013;11:412-422.

19. Chong LY, Fenu E, Stansby G, Hodgkinson S; Guideline Development Group. Management of venous thromboembolic diseases and the role of thrombophilia testing: summary of NICE guidance. BMJ 2012;344:e3979.

2o. van der Meer RW, Pattynama PM, van Strijen MJ, et al. Right ventricular dysfunction and pulmonary obstruction index at helical CT: prediction of clinical outcome during 3-month follow-up in patients with acute pulmonary embolism. Radiology 2005;235:798-803.
21. Ghuysen A, Ghaye B, Willems V, et al. Computed tomographic pulmonary angiography and prognostic significance in patients with acute pulmonary embolism. Tho$\operatorname{rax} 2005 ; 60: 956-961$.

22. Taylor FB Jr, Toh CH, Hoots WK, Wada H, Levi M; Scientific Subcommittee on Disseminated Intravascular Coagulation (DIC) of the International Society on Thrombosis and Haemostasis (ISTH). Towards definition, clinical and laboratory criteria, and a scoring system for disseminated intravascular coagulation. Thromb Haemost 2001;86:13271330.

23. Levi M. Current understanding of disseminated intravascular coagulation. Br J Haematol 2004;124:567-576.

24. D'Angelo A, Vigano-D'Angelo S, Esmon CT, Comp PC. Acquired deficiencies of protein $\mathrm{S}$ : protein $\mathrm{S}$ activity during oral anticoagulation, in liver disease, and in disseminated intravascular coagulation. J Clin Invest 1988;81:1445-1454.

25. Bucciarelli P, Rosendaal FR, Tripodi A, et al. Risk of venous thromboembolism and clinical manifestations in carriers of antithrombin, protein $\mathrm{C}$, protein $\mathrm{S}$ deficiency, or activated protein $\mathrm{C}$ resistance: a multicenter collaborative family study. Arterioscler Thromb Vasc Biol 1999;19:1026-1033.

26. Koster T, Blann AD, Briet E, Vandenbroucke JP, Rosendaal FR. Role of clotting factor VIII in effect of von Willebrand factor on occurrence of deep-vein thrombosis. Lancet 1995;345:152-155.

27. Wells PS, Langlois NJ, Webster MA, Jaffey J, Anderson JA. Elevated factor VIII is a risk factor for idiopathic venous thromboembolism in Canada: is it necessary to define a new upper reference range for factor VIII? Thromb Haemost 2005;93:842-846.

28. Broekmans AW, Bertina RM, Reinalda-Poot J, et al. Hereditary protein $\mathrm{S}$ deficiency and venous thrombo-embolism: a study in three Dutch families. Thromb Haemost 1985;53:273-277.

29. Levi M, Schultz M, van der Poll T. Disseminated intravascular coagulation in infectious disease. Semin Thromb Hemost 2010;36:367-377.

30. Engesser L, Broekmans AW, Briet E, Brommer EJ, Bertina RM. Hereditary protein S deficiency: clinical manifestations. Ann Intern Med 1987;106:677-682. 